\title{
Predicting High-Power Performance in Professional Cyclists
}

Citation for published version (APA):

Sanders, D., Heijboer, M., Akubat, I., Meijer, K., \& Hesselink, M. K. (2017). Predicting High-Power Performance in Professional Cyclists. International Journal of Sports Physiology and Performance, 12(3), 410-413. https://doi.org/10.1123/ijspp.2016-0134

Document status and date:

Published: 01/03/2017

DOI:

10.1123/ijspp.2016-0134

Document Version:

Publisher's PDF, also known as Version of record

Document license:

Taverne

Please check the document version of this publication:

- A submitted manuscript is the version of the article upon submission and before peer-review. There can be important differences between the submitted version and the official published version of record.

People interested in the research are advised to contact the author for the final version of the publication, or visit the DOI to the publisher's website.

- The final author version and the galley proof are versions of the publication after peer review.

- The final published version features the final layout of the paper including the volume, issue and page numbers.

Link to publication

\footnotetext{
General rights rights.

- You may freely distribute the URL identifying the publication in the public portal. please follow below link for the End User Agreement:

www.umlib.nl/taverne-license

Take down policy

If you believe that this document breaches copyright please contact us at:

repository@maastrichtuniversity.nl

providing details and we will investigate your claim.
}

Copyright and moral rights for the publications made accessible in the public portal are retained by the authors and/or other copyright owners and it is a condition of accessing publications that users recognise and abide by the legal requirements associated with these

- Users may download and print one copy of any publication from the public portal for the purpose of private study or research.

- You may not further distribute the material or use it for any profit-making activity or commercial gain

If the publication is distributed under the terms of Article $25 \mathrm{fa}$ of the Dutch Copyright Act, indicated by the "Taverne" license above, 


\title{
Predicting High-Power Performance in Professional Cyclists
}

\author{
Dajo Sanders, Mathieu Heijboer, Ibrahim Akubat, Kenneth Meijer, and Matthijs K. Hesselink
}

\begin{abstract}
Purpose: To assess if short-duration (5 to $\sim 300 \mathrm{~s}$ ) high-power performance can accurately be predicted using the anaerobic power reserve (APR) model in professional cyclists. Methods: Data from 4 professional cyclists from a World Tour cycling team were used. Using the maximal aerobic power, sprint peak power output, and an exponential constant describing the decrement in power over time, a power-duration relationship was established for each participant. To test the predictive accuracy of the model, several all-out field trials of different durations were performed by each cyclist. The power output achieved during the all-out trials was compared with the predicted power output by the APR model. Results: The power output predicted by the model showed very large to nearly perfect correlations to the actual power output obtained during the all-out trials for each cyclist $(r=.88 \pm .21, .92 \pm .17, .95 \pm .13$, and $.97 \pm .09)$. Power output during the all-out trials remained within an average of $6.6 \%(53 \mathrm{~W})$ of the predicted power output by the model. Conclusions: This preliminary pilot study presents 4 case studies on the applicability of the APR model in professional cyclists using a field-based approach. The decrement in all-out performance during high-intensity exercise seems to conform to a general relationship with a single exponential-decay model describing the decrement in power vs increasing duration. These results are in line with previous studies using the APR model to predict performance during brief all-out trials. Future research should evaluate the APR model with a larger sample size of elite cyclists.
\end{abstract}

Keywords: training, anaerobic power, aerobic power, cycling

In cycling, mainly an aerobic marker such as power output at maximal oxygen uptake $\left(\mathrm{VO}_{2} \mathrm{max}\right)$ or functional threshold power is used as a reference to set intensity for high-intensity interval training (HIT). ${ }^{1}$ In practice however, 2 cyclists with similar power output at $\mathrm{VO}_{2}$ max can have significantly different sprint peak power outputs. Therefore, if the intensity of a HIT session is exclusively based on a percentage of power output at $\mathrm{VO}_{2} \max$ (eg, intervals at $130 \%$ of power output at $\mathrm{VO}_{2} \max$ ), the athlete with the higher sprint peak power output has to work at a lower percentage of his or her maximal anaerobic capacity, which results in a different physiological demand and exercise tolerance. ${ }^{2}$ Therefore, exercise intensity of supramaximal HIT should be individualized based on a combination of aerobic and anaerobic capacity to have the same training impact among different individuals. $^{2}$

The anaerobic power reserve (APR) is defined as the difference between maximal sprint peak power output and power output at $\mathrm{VO}_{2}$ max. ${ }^{3}$ Studies have used the APR range to set the minimal and maximal values of a high-power duration curve. With this powerduration curve, the performance of all-out efforts lasting from a few seconds to a few minutes can be predicted. ${ }^{3-6}$ This individual power-duration curve obtained by the APR model could be useful in prescribing exercise intensity and work durations for (supramaximal) HIT. ${ }^{2}$ The principle of this model is based on the assumption that the exponential decrement in high-power performance in relation to duration is the same for different athletes in relation to their APR. ${ }^{3,5}$ However, it remains questionable if the APR is applicable

Sanders and Akubat are with Sport, Exercise and Health Research Centre, Newman University, Birmingham, UK. Heijboer is with Team LottoNLJumbo professional cycling team, Amsterdam, the Netherlands. Meijer and Hesselink are with the Dept of Human Movement Science, School for Nutrition, Toxicology and Metabolism, MUMC+, Maastricht, Netherlands. Address author correspondence to Dajo Sanders at dajosanders@ gmail.com. in high-level (endurance) athletes such as professional cyclists. ${ }^{7}$ Furthermore, evidence of the applicability of a field-based approach to the APR concept could be valuable for coaches and practitioners. This report presents 4 case studies assessing the applicability of the APR model in professional cyclists using field-based tests.

\section{Methods}

\section{Subjects}

Four high-level endurance athletes from a Union Cycliste Internationale (UCI) World Tour professional road cycling team participated in this investigation (mean \pm SD age $30 \pm 5 \mathrm{y}$, height $1.83 \pm 0.04 \mathrm{~m}$, body mass $74.9 \pm 4.3 \mathrm{~kg}$ ). Data were collected from routine exercise testing and training of the cyclists. Permission was obtained from the team and cyclists for the use of this data.

\section{Testing}

Power at maximal aerobic capacity was determined using an incremental field test protocol. Each cyclist performed 6 stages consisting of 6 minutes each on uphill terrain (mean gradient of $4.8 \%$ ). Based on preseason laboratory testing, individual guidelines for the power output for each stage were provided for the riders before the field test (average increment of $31 \pm 4 \mathrm{~W} /$ interval). After the 6-minute interval, the riders had 6 to 10 minutes of active recovery $(<55 \%$ of power output at anaerobic threshold) before starting the next interval. The last effort was a 6-minute all-out performance; the mean output during these 6 minutes was used as the maximal aerobic capacity. ${ }^{2,8}$ Power output was measured using a mobile ergometer system (Pioneer Power Meter, Kawasaki, Kanagawa, Japan). Although no pulmonary gas exchange measures were taken during this test, power output during the last block of an incremental test is largely correlated with maximal aerobic capacity. ${ }^{2}$ Sprint peak power output was defined as the maximal peak 1-second power output the cyclists could achieve 
during all-out standing sprints in the field. Before the incremental field test, 3 maximal sprint trials of 10 seconds were performed. The sprints were performed as "flying sprints" with the cyclist already riding at 30 to $35 \mathrm{~km} / \mathrm{h}$. The cyclists performed the sprints on their own bike with a cadence preferred by the cyclists $(99 \pm 7 \mathrm{rpm})$.

\section{Anaerobic Power Reserve}

Based on the anaerobic reserve model, a power-duration relationship was established individually for each subject. This relationship was set using the following formula ${ }^{3}$ :

$$
\mathrm{PO}_{\mathrm{t}}=\mathrm{PO}_{\mathrm{aer}}+\left(\mathrm{PO}_{\mathrm{sp}}-\mathrm{PO}_{\mathrm{aer}}\right) \times e(-k \times t)
$$

where $t$ is the duration of the all-out trial, $\mathrm{PO}_{\mathrm{t}}$ is the power output maintained for that trial with a duration of $t, \mathrm{PO}_{\mathrm{aer}}$ is the power output at maximal aerobic capacity, $\mathrm{PO}_{\mathrm{sp}}$ is the sprint peak power output, $e$ is the base of the natural logarithm, and $k$ is the exponent that describes the decrement in power output over time. The exponential time constant describing the decrement in power over time used in this study is based on the previous established exponential power-duration curve fitted through data in recreationally active cyclists $(k=0.026) .4,5$

\section{All-Out Efforts}

Several all-out efforts of different durations (5-120 s) were performed by each cyclist in a 4-week period. Every week, 3 all-out trials were incorporated into the training program. The trial was performed after a warm-up of 20 to 30 minutes (50-75\% of power output at anaerobic threshold). The cyclists performed the efforts on their own bike with a cadence preferred by the cyclists $(91 \pm 6 \mathrm{rpm})$. Measured power outputs of the all-out trials were compared with the power output predicted by the APR model, providing individual correlation coefficients $(r)$. Statistical interpretations and scale of magnitudes were based on the guidelines provides by Hopkins et al. ${ }^{9}$

\section{Results}

Power output achieved during the last 6-minute block of the incremental field test for the 4 subjects averaged $477 \pm 24 \mathrm{~W}$ (range 444-501 W) and 6.4 $\pm 0.4 \mathrm{~W} / \mathrm{kg}$ (Figure 1). The maximal power output achieved during the standing all-out sprints had an average value of $1317 \pm 210 \mathrm{~W}$ (range 1036-1525 W) and $17.5 \pm 2.3 \mathrm{~W} /$ kg (Figure 1).

Twenty-seven all-out trials were performed by the 4 subjects, varying from an all-out performance of 5 seconds up to 120 seconds in the 4-week period after the APR field tests. Even though substantial differences could be seen between subjects in absolute power outputs achieved during the all-out trials (Figure 1), when comparing the power output predicted by the APR model with the actual power output obtained during the all-out trials, very large to nearly perfect relationships were observed for the 4 subjects (Figure 2). Correlations coefficients $\left( \pm 90 \%\right.$ confidence limits $\left.^{9}\right)$ observed were $r=.88 \pm .21$, $.92 \pm .17, .95 \pm .13$, and $.97 \pm .09$ for each subject, respectively. Power output during the all-out trials remained within an average of 6.6\% (53 $\mathrm{W})$ of the predicted power output by the model $(r=.96)$ (Figure 3 ).

\section{Discussion}

This study presents 4 case studies of the applicability of the APR model in professional cyclists using a field-based approach. The APR model estimated a total of 27 trials from 4 professional

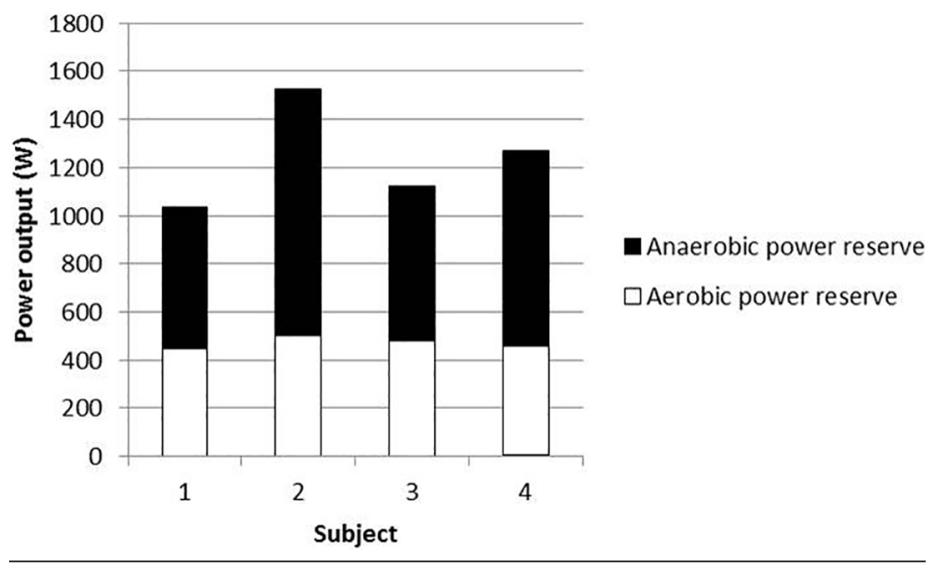

Figure 1 - Maximal sprint peak power output and maximal aerobic power output for each of the 4 subjects.

cyclists within an average of $6.6 \%$. Results were lower compared with previously determined predictability for running $(3.7 \%$ and $2.6 \%)^{4,6}$ and similar to predictability reported for high-power cycling performance $(6.6 \%){ }^{3}$ It remains a challenge to do research in elite athletes with a large group of participants. However, even with a limited sample size, testing the applicability of these concepts in elite athletes could prove valuable for coaches and practitioners working with these athletes as they cannot rely solely on research with less trained subjects.

One aspect that needs to be taken into account is the individual differences in the applicability of the model. For participant 1 , the model mostly overestimated the power output that was actually achieved during the all-out trials $(r=.88)$, and in participant 4 the model mostly predicted lower power outputs than actually achieved during the trials $(r=.92)$. Motivation, pacing, and postrace fatigue play important roles in the performance achieved during the all-out efforts, especially when taking into account the busy race schedule of these athletes.

A second important aspect is the testing methods to assess the anaerobic reserve range. The field tests used in this study are slightly different and less controlled compared with previous (laboratory) protocols used in Weyand et al. ${ }^{3}$ However, because of the intrusiveness of laboratory testing on the cyclists' training or competition program, field testing is more applied on a regular base in these athletes. Therefore, evidence of the applicability of a field-based approach to the APR concept is valuable for coaches and practitioners.

\section{Practical Applications}

By using 2 simple field tests to assess maximal aerobic power and maximal sprint peak power output, a power-duration curve from 5 to $\sim 300$ seconds can be established individually for each athlete. The power-duration curve predicted by the APR model can contribute to a more accurate and individualized training program. ${ }^{2,10}$ The application of different work to rest ratios in HIT and the impact on the type of adaptation has previously been discussed in research. ${ }^{2}$ The APR model may help coaches set the correct intensities for different work to rest ratios to achieve the desired adaptation for cyclists with differing competition goals. 

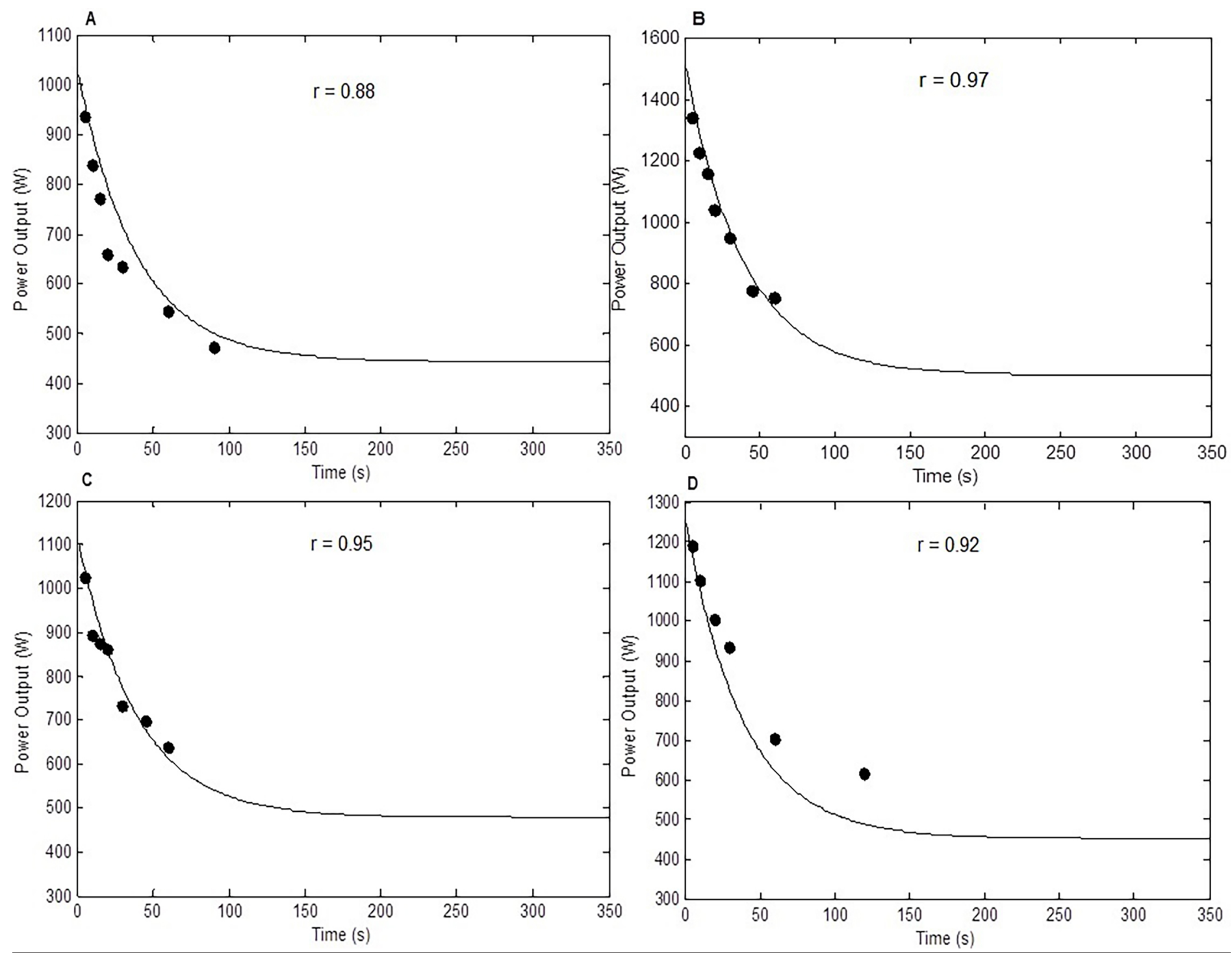

Figure 2 - Power duration curves for participant (A) 1, (B) 2, (C) 3, and (D) 4 when comparing predicted power outputs (line) with the all-out trials (black circles).

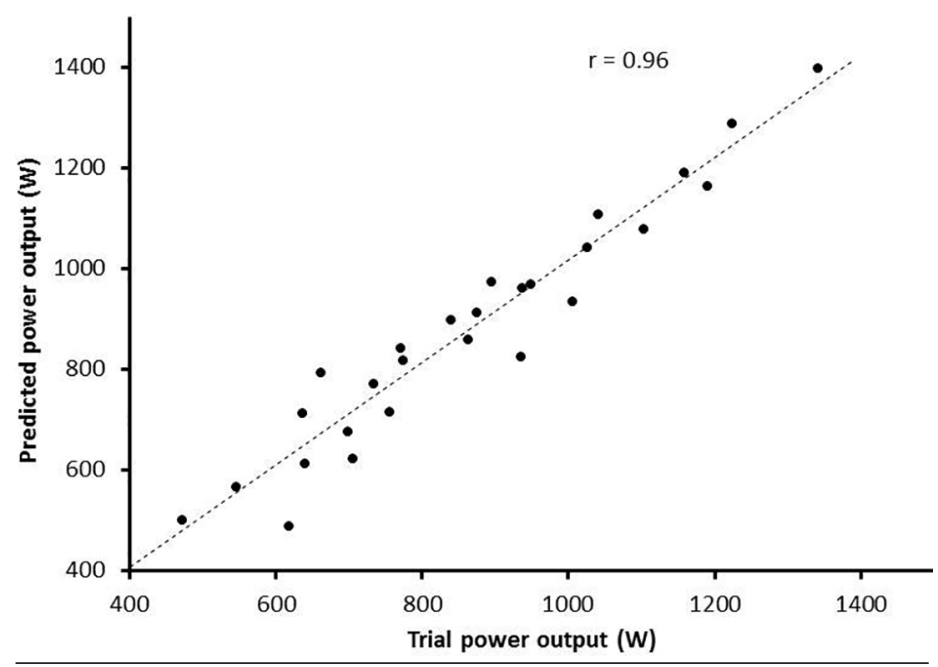

Figure 3 - Predicted power output by the anaerobic power reserve model versus actual power output achieved during all-out efforts.

\section{Conclusions}

This preliminary investigation shows 4 case studies on the applicability of the APR model in professional cyclists using a fieldbased approach. These results are in line with previous studies using an anaerobic power/speed model to predict performance during brief all-out trials. ${ }^{3,4,6}$ The determination of an APR range can contribute to the individualization of training intensity and demand during HIT sessions. Results should be considered promising with a view to verifying them with a larger pool of athletes.

\section{Acknowledgments}

The authors would like to thank Melvin Kantebeen (ConTest, sports consultancy) and Louis Delahaije (Lotto-NL Jumbo cycling team) for their help collecting the laboratory and field data. Furthermore, we would like to thank the cyclists for their participation in this investigation. 


\section{References}

1. Laursen PB, Jenkins DG. The scientific basis for high-intensity interval training: optimising training programmes and maximising performance in highly trained endurance athletes. Sports Med. 2002;32(1):53-73. PubMed doi:10.2165/00007256-200232010-00003

2. Buchheit M, Laursen PB. High-intensity interval training, solutions to the programming puzzle: part I: cardiopulmonary emphasis. Sports Med. 2013;43(5):313-338. PubMed doi:10.1007/s40279-013-0029-x

3. Weyand PG, Lin JE, Bundle MW. Sprint performance-duration relationships are set by the fractional duration of external force application. Am J Physiol Regul Integr Comp Physiol. 2006;290(3):R758-R765. PubMed doi:10.1152/ajpregu.00562.2005

4. Bundle MW, Hoyt RW, Weyand PG. High-speed running performance: a new approach to assessment and prediction. $J$ Appl Physiol. 2003;95(5):1955-1962. PubMed doi:10.1152/japplphysiol.00921.2002

5. Bundle MW, Weyand PG. Sprint exercise performance: does metabolic power matter? Exerc Sport Sci Rev. 2012;40(3):174-182. PubMed
6. Weyand PG, Bundle MW. Energetics of high-speed running: integrating classical theory and contemporary observations. Am J Physiol Regul Integr Comp Physiol. 2005;288(4):R956-R965. PubMed doi:10.1152/ajpregu.00628.2004

7. Lucía A, Pardo J, Durantez A, Hoyos J, Chicharro JL. Physiological differences between professional and elite road cyclists. Int J Sports Med. 1998;19(5):342-348. PubMed doi:10.1055/s-2007-971928

8. Billat V, Faina M, Sardella F, et al. A comparison of time to exhaustion at $\mathrm{VO}_{2}$ max in elite cyclists, kayak paddlers, swimmers and runners. Ergonomics. 1996;39(2):267-277. PubMed doi:10.1080/00140139608964457

9. Hopkins WG, Marshall SW, Batterham AM, Hanin J. Progressive statistics for studies in sports medicine and exercise science. Med Sci Sports Exerc. 2009;41(1):3-13. PubMed doi:10.1249/ MSS.0b013e31818cb278

10. Blondel N, Berthoin S, Billat V, Lensel G. Relationship between run times to exhaustion at $90,100,120$, and $140 \%$ of $v \mathrm{VO}_{2}$ max and velocity expressed relatively to critical velocity and maximal velocity. Int $J$ Sports Med. 2001;22(1):27-33. PubMed doi:10.1055/s-2001-11357 